\title{
Banco de Dentes Humanos para o Ensino e Pesquisa em Odontologia
}

\section{Human Teeth Bank for Education and Research in Dentistry}

Letícia Moreira', Bruna Genari ${ }^{2}$, Ruggiero Stello², Fabrício Mezzomo Collares ${ }^{3}$, Susana Maria Werner Samuel ${ }^{4}$

\section{Abstract}

The use of human teeth for teaching/education and research in dentistry is a common practice. The establishment of Human Teeth Bank (BDH) in institutions of education is essential to enable the safe handling in teaching, research and the discovery of new technologies which make use of human teeth. Before BDH establishment is appropriate, its organization and legalization must be disclosed. Procedures of collection, cleaning and disinfection, separation and storage, disposal and/or loan and biosecurity should be developed and improved. The aim of this study is to search the number of BDH inside schools of Dentistry units at Rio Grande do Sul state and to review the literature about the importance of $\mathrm{BDH}$ in institutions of education and research as well as its legal, technical and scientific aspects.

Keywords: Human teeth bank. Biosecurity. Education, dental.

\section{Resumo}

O uso de dentes humanos para o ensino e pesquisa em Odontologia é uma prática freqüente. A implantação de Bancos de Dentes Humanos $(\mathrm{BDH})$ em instituições de ensino é fundamental para viabilizar a manipulação segura para aprendizagem, pesquisa e inovações tecnológicas que façam uso de dentes humanos. Para que seu funcionamento seja adequado, a organização e a legalização do uso de dentes devem ser divulgadas. Procedimentos relativos às etapas de arrecadação, limpeza e desinfecção, separação e armazenamento, cessão e/ou empréstimo e de biossegurança devem ser desenvolvidos, aprimorados e colocados ao alcance dos interessados. Este artigo tem como objetivo fazer um levantamento do número de $\mathrm{BDH}$ em instituições de ensino de Odontologia do Estado do Rio Grande do Sul e buscar na literatura orientações disponíveis sobre os aspectos práticos, legais, técnicos e científicos necessários ao seu funcionamento em instituições de ensino e pesquisa em Odontologia.

Palavras-chave: Banco de dentes humanos. Biossegurança. Educação em Odontologia.
1 Farmacêutica- Técnica do Laboratório de Materiais Dentários (LAMAD) da Faculdade de Odontologia da UFRGS

${ }^{2}$ Bolsistas do Grupo PET do Curso de Odontologia- Faculdade de Odontologia da Universidade Federal do Rio Grande do Sul (UFRGS)

${ }^{3}$ Professor Adjunto da Disciplina de Materiais Dentários, Universidade Federal do Rio Grande do Sul

${ }^{4}$ Professora Titular da Disciplina de Materiais Dentários, Universidade Federal do Rio Grande do Sul

Correspondência: Susana Maria Werner Samuel

Endereç: R. Ramiro Barcelos, 2492 - CEP 90035003, Porto Alegre - RS, Brasil Fone/fax: (51) 3308-5197

E-mail: samuelsp@adufrgs.ufrgs.br

Data de Submissão: 16/04/2009

Data de Aceite: 14/10/2009

\section{Introdução}

O uso de dentes humanos extraídos é fundamental para consolidar o ensino e a pesquisa nos cursos de Odontologia. Através da Lei de Transplantes no Brasil (BRASIL, 1997), os dentes passaram a ser considerados órgãos. Sendo o dente um órgão do corpo humano, sua origem deve ser conhecida. Neste contexto, a fonte legal da disponibilização de dentes é um Banco de Dentes Humanos (BDH). Para que os dentes possam ser utilizados para fins acadêmicos, há necessidade de serem doados a uma instituição que possua um BDH. Essa doação deve ser formal e um termo de Consentimento Livre e Esclarecido deve ser preenchido pelo doador (NASSIF et al., 2003a), esse documento legaliza e mostra que o doador autoriza a doação e está ciente de que a extração é a terapêutica mais adequada no seu tratamento (VANZELLI et al., 2003).

Os dentes extraídos são potenciais fontes de contaminação, e é fundamental que o BDH proceda a descontaminação dos mesmos. Sendo assim, um BDH tem também o importante papel de prevenir a infecção cruzada existente no manuseio indiscriminado de dentes extraídos, visto que alguns patógenos podem sobreviver por um longo tempo, mesmo sobre substratos secos (DOMINICl et al., 2001). Além disso, o $\mathrm{BDH}$ deve possuir condições de armazenar os dentes em condições que permitam a manutenção de suas propriedades químicas, físicas e mecânicas para permitir também a realização dos trabalhos de pesquisa com controle de vieses.

A produção científica disponível nesta área é bastante escassa e muitas vezes a implantação dos BDHs ocorre em função de iniciativas isoladas, graças à troca de informações entre instituições que vivenciaram a experiência e as dificuldades de implantação do próprio BDH.

Para facilitar a necessária implantação dos BDHs deveria haver mais informações e orientações sobre os mecanismos de sua implantação incluindo aspectos como etapas de arrecadação, limpeza e desinfecção, separação e armazenamento, cessão e/ou empréstimo e biossegurança. Além disso, é importante divulgar em que situação se encontram as instituições de ensino de Odontologia do Estado do Rio Grande do Sul no que se refere à existência de $\mathrm{BDHs}$. 
Considerando a necessidade e importância da regulamentação dos $\mathrm{BDH}$, os objetivos deste trabalho são: fazer um levantamento do número de $\mathrm{BDH}$ em instituições de ensino de Odontologia do Estado do Rio Grande do Sul e mostrar os resultados de uma busca na literatura acerca dos aspectos práticos, legais, técnicos e científicos, necessários para a implantação de um $\mathrm{BDH}$, numa instituição de ensino e pesquisa em Odontologia.

\section{Métodos e Resultados}

Levantamento do número de $\mathrm{BDH}$ em instituições de ensino de Odontologia do Estado do Rio Grande do Sul.

Segundo o Conselho Federal de Odontologia (CFO), existem atualmente, no Estado do Rio Grande do Sul, 12 Faculdades de Odontologia. Através de contato telefônico, realizado entre 23 de setembro e $1^{\circ}$ de outubro de 2009 , somente cinco destas faculdades informaram possuir BDH em funcionamento, em suas instituições. Quanto às sete outras universidades, seis declararam não ter BDH e de uma delas não foi possível obter a informação, mesmo após várias tentativas.

\section{Revisão da literatura}

A revisão da literatura foi realizada utilizando os termos de busca "extracted teeth/dentes extraídos", "extracted human teeth/dentes humanos extraídos", "human teeth bank/ banco de dentes humanos", "teeth storage/armazenamento de dentes" e "esterilização de dentes/teeth sterilization". Foram consultadas as bases de dados Web of Science (Capes/Fapesp), Cochrane Library, Micromedex, Sciencedirect, Medline-Pubmed e LILACS. Não foram feitas restrições de período nas bases e a busca foi realizada entre 10 de fevereiro e 31 de março de 2009. Também foi pesquisada literatura elaborada por pesquisadores de Bancos de Dentes Humanos já existentes, como por exemplo, do BDH da Faculdade de Odontologia da Universidade de São Paulo (USP), que tem sido considerado modelo para implantação de BDHs no Brasil.

\section{Valorização do dente como órgão}

A utilização de dentes humanos para fins de pesquisa ou realização de procedimentos laboratoriais ou clínicos deve respeitar aspectos éticos e legais, e precisa ser uma preocupação de pesquisadores, educadores, alunos e da população em geral (VANZELLI; IMPARATO, 2003).

Ferreira et al. (2003) consideram a implantação de BDH em instituições de ensino um processo irreversível e fundamental, justamente porque promovem a utilização do órgão dental de forma ética.

O elemento dental, em geral, não tem recebido o merecido valor, por pesquisadores, professores ou alunos que utilizam quantidades indiscriminadas de dentes humanos em seus trabalhos, desconsiderando os aspectos éticos e legais envolvidos em seu uso. É fundamental que o uso dos dentes seja feito de forma racional para evitar algumas práticas ainda hoje encontradas (VANZELLI et al., 2003), como por exemplo, o comércio de dentes, que pode ocorrer a partir de cemitérios, clínicas odontológicas e, até mesmo, dentro de faculdades, envolvendo funcionários, técnicos de laboratório e alunos (GABRIELLI FILHO; IMPARATO, 2003).

Descrições da prática ilegal referente ao comércio de dentes e ossos humanos entre funcionários de cemitérios em que repórteres, fazendo-se passar por estudantes da área da saúde, negociaram com coveiros e efetuaram a compra do material evidenciando a desvalorização de dentes e ossos como órgãos, são comuns. Um exemplo do exposto encontra-se na página do Ministério Público do Estado do Rio Grande do Sul (RIO GRANDE DO SUL, 2009).

Nassif et al. (2003a) consideram o BHD uma instituição sem fins lucrativos, que tem entre suas funções a valorização e divulgação do dente como órgão, a arrecadação, preparação, cessão e/ou empréstimo de dentes, administração dos dados e registros e a realização de pesquisas e atividades didáticas.

Atualmente se sabe que os tecidos do corpo humano são potenciais fontes de DNA e, portanto, podem ser utilizados, como por exemplo, para análise forense, porém os tecidos humanos em geral podem sofrer contaminação ambiental ou sofrer decomposição quando submetidos a grandes variações de pressão e temperatura. Os dentes, por sua vez, resistem mais à degradação post mortem, e por isso podem preservar a informação genética contida no DNA e ser uma alternativa para identificação genética de indivíduos (SILVA, 1997).

Assim, dentes preservados, identificados e armazenados de maneira apropriada em um BDH podem auxiliar a Odontologia Forense na identificação humana e também nas pesquisas com DNA dentário (TIERI et al., 2003).

\section{Divulgação}

Os objetivos e atividades do BDH devem ser divulgados para conhecimento da comunidade, através de programas, projetos, palestras e publicações na mídia escrita e/ou falada. A divulgação da importância das doações de dentes sob a forma de campanhas é imprescindível para tornar possível a manutenção das atividades do BDH (BARRETO et al., 2003). É importante incentivar a arrecadação dos dentes humanos, pois através das doações é possível a complementação e manutenção de um estoque de dentes suficiente para suprir as necessidades de ensino e de pesquisas da instituição a que o BDH está vinculado (NASSIF, 2003b). Os dentes podem ser arrecadados de diversas fontes, desde clínicas particulares até postos de saúde do município sede do BDH e dos municípios vizinhos. Parcerias com prefeituras $\mathrm{e}$ órgãos administrativos podem vir a aumentar a doação de dentes para o BDH das instituições.

\section{Aspectos Legais}

A origem dos dentes é um aspecto legal que deve levado em consideração. A Lei de Transplantes no Brasil (BRASIL, 1997) não permite a remoção, ainda post-mortem, de "tecidos, órgãos ou partes corpo de pessoas não identificadas" e prevê pena de 3 a 8 anos de reclusão e multa para quem compra ou vende e incorre na mesma pena quem promove, intermedeia, facilita ou aufere qualquer vantagem com a transação. Segundo o Código Penal Brasileiro, no artigo 210 do Capítulo II- Dos Crimes Contra o Respeito aos Mortos, quem "violar ou profanar sepultura ou urna funerária" pode pagar com pena de 1 a 3 anos de reclusão e multa (BRASIL, 2009).

Tanto para dentes decíduos quanto para dentes permanentes, o paciente deve ser questionado se aceita doar o(s) dente(s) e orientado a respeito do destino dado a eles e, caso esteja de acordo, deverá assinar o Termo de Consentimento Livre e Esclarecido (TCLE). Esse termo contém informações sobre o destino e finalidade dos dentes doados e é individual, podendo ser usado em clínicas particulares, postos de saúde, clínicas de instituições de ensino e hospitais (NASSIF, 2003b).

$\mathrm{Na}$ impossibilidade de se obter o consentimento de doação de cada um dos doadores, quando os dentes já estão armazenados, sem 0 cumprimento dos procedimentos bioéticos, sob a responsabilidade de um cirurgião-dentista, de um aluno da graduação ou de um indivíduo da população em geral, pode-se utilizar um Termo de Doação de Dentes Humanos (TDDH) (NASSIF, 2003b). Trata-se 
do documento que oficializa a doação dos dentes em poder desse indivíduo, ao $\mathrm{BDH}$ e esclarece que o destino dado aos mesmos é em favor principalmente do ensino e pesquisa.

\section{Organização}

No que tange a organização, diretrizes e normas de funcionamento de um Banco de dentes, visando o comprimento da legislação vigente, é importante a existência de um vínculo entre o Banco de Dentes e o Comitê de Ética em Pesquisa (CEP) da Instituição a qual esteja vinculado (BRASIL et al., 2003).

Atualmente os projetos de pesquisa que usam dentes humanos e cuja origem não é comprovada e/ ou legalizada, dificilmente são aprovados pelos CEPs. Esse é outro motivo importante que torna a implantação de um $\mathrm{BDH}$ necessária e importante nas faculdades de odontologia (NASSIF, 2003b).

$\mathrm{O} \mathrm{BDH}$ deve ser caracterizado por sua organização criteriosa. Seu valor não se restringe somente a faculdade, mas também à população que é beneficiada na medida em que o ensino e a pesquisa com dentes aperfeiçoam os estudos pré-clínicos e de futura aplicação clínica, promovendo uma redução do comércio ilegal de dentes (NASSIF, 2003b).

A organização dos dentes extraídos e coletados pode ser de acordo com critérios qualitativos de higidez, presença de lesão de cárie e/ou restaurações de amálgama, restaurações com outros materiais, anômalos e fraturados. Os dentes também podem ser organizados e armazenados de acordo com o tipo de dente (incisivos, caninos, pré-molares e molares permanentes ou incisivos, caninos e molares decíduos). É recomendável a adoção de protocolos para procedimentos importantes no funcionamento de um $\mathrm{BDH}$, tais como a separação, limpeza, desinfecção/esterilização e armazenamento dos dentes (NASSIF, 2003b).

\section{Descontaminação e Armazenamento}

Os dentes que são doados ao $\mathrm{BDH}$ devem passar por procedimentos padronizados, de descontaminação e armazenagem, baseados em pesquisas científicas (NASSIF, 2003b).

Tecidos presentes na estrutura dental, como a polpa e a raiz, podem conter patógenos como o vírus da hepatite $\mathrm{B}$, vírus HIV e inúmeros outros de origem hematogênica (WHITE; HAYS, 1995).

A manipulação dos elementos dentais deve ser feita somente por indivíduo paramentado com os equipamentos de proteção individual (EPI), a fim de evitar a contaminação cruzada. A preparação, seleção e os métodos de desinfecção/ esterilização dos dentes podem variar de acordo com a pesquisa e, principalmente, com a finalidade para a qual os dentes se destinam (NASSIF, 2003b).

Vários métodos de descontaminação e armazenamento de dentes têm sido utilizados em pesquisas, no entanto a ação desses agentes não deve modificar características importantes do tecido dentário, tais como a resistência de união à dentina e a microinfiltração.

Costa et al. (2007) avaliaram a procedência, utilização, descontaminação e o armazenamento dos dentes humanos usados no ensino odontológico e confirmaram a existência do comércio ilegal de dentes, também verificaram que a descontaminação anterior ao manuseio dos dentes é realizada por $89,8 \%$ dos acadêmicos pesquisados, apesar de muitos dos métodos serem insuficientes para garantir a prevenção do risco de infecção cruzada. Foram descritos 30 procedimentos diferentes, desde lavagem com água até esterilização em autoclave. Concluíram também que a maioria $(96,6 \%)$ armazena os dentes em frascos fechados sendo $68,0 \%$ destes, imersos em soluções de hipoclorito de sódio. Entre pesquisadores não existe consenso sobre o meio de armazenagem mais adequado. Campregher et al. (2007) encontraram 41 tipos diferentes de meios de armazenagem de dentes extraídos em três periódicos pesquisados. Além disso, grande parte dos artigos pesquisados não citava o meio utilizado.

\section{Administração, Empréstimo e Cessão}

Para controle dos dentes do $\mathrm{BDH}$, aqueles usados por alunos da graduação são emprestados e, ao término das disciplinas solicitantes, devem ser devolvidos, independentemente do grau de destruição ou desgaste que apresentem. Aos pesquisadores os dentes podem ser cedidos ou emprestados, dependendo do tipo de teste a que serão submetidos durante a pesquisa (NASSIF, 2003b).

Ao solicitar os dentes ao $\mathrm{BDH}$, os alunos ou pesquisadores primeiramente devem preencher um cadastro, termos de solicitação e compromisso de citação, tanto em caso de empréstimo quanto de cessão, para que se tenha controle de sua destinação final. No caso de pesquisa, é recomendável que um projeto seja anexado juntamente com o parecer favorável do Comitê de Ética em Pesquisa (CEP) para realização do trabalho (NASSIF, 2003b).

A coordenação geral do $\mathrm{BDH}$, normalmente fica a cargo de um cirurgião-dentista e professor da Instituição de Ensino à qual está vinculado. Ele deve definir, estabelecer e desenvolver as atribuições dos demais membros do BDH (NASSIF, 2003b).

Segundo Nassif (2003b), a administração de um BDH requer dedicação e rigor no cumprimento de suas atribuições para que adquira respeito e reconhecimento de suas finalidades.

\section{Considerações Finais}

É notório que a implantação de um Banco de Dentes é fundamental em uma instituição de ensino e pesquisa na área de odontologia, visto que eleva a qualidade do aprendizado, proporciona segurança física e legal aos indivíduos e possibilita uma ampliação das possibilidades de avanço na área tecnológica. Mesmo assim, mais de $50 \%$ das Faculdades de Odontologia do Estado do Rio Grande do Sul não possuem Banco de Dentes Humanos. Ações no sentido de estimular a implantação dos Bancos de Dentes fazem-se necessárias. Sabe-se que a consolidação de um BDH depende do apoio da comunidade, dos alunos, dos docentes, pesquisadores e muito especialmente da diretoria da instituição.

Espera-se que esta revisão na literatura, ainda que escassa, facilite a elaboração de um roteiro que oriente as ações de implantação de BDHs e ainda reforce a sua importância.

\section{Referências}

BARRETO, P. A. et al. Programas e Campanhas de Doação de Dentes Humanos. In: IMPARATO, J. C. P. et al. Banco de Dentes Humanos. Curitiba: Maio, 2003. Cap. 3, p. 37-50.

BRASIL. Lei no 9434, de 4 de fevereiro de 1997. Dispõe sobre a Remoção de Órgãos, Tecidos e Partes do Corpo Humano para Fins de Transplante e Tratamento e dá outras Providências. Diário Oficial [da] República Federativa do Brasil, Brasília, DF, 5 fev. 1997. Disponível em:

$<$

http://www6.senado.gov.br/legislacao/ListaTextolntegral.action?id=12 3711>. Acesso em: 5 fev. 2009.

BRASIL, S. A. et al. Relação entre Bancos de Dentes e Comitês de Ética. In: IMPARATO, J. C. P. et al. Banco de Dentes Humanos. Curitiba: Maio, 2003. Cap. 11, p. 151-162. 
BRASIL. Código Penal e Constituição Federal. 47. ed. São Paulo: Saraiva, 2009.

CAMPREGHER, U. B.; ARRUDA, F. Z.; SAMUEL, S. W. Meios Utilizados para Armazenagem de Dentes em Pesquisas Odontológicas de Impacto: uma Revisão Sistemática. RPG. Rev. Pós Grad. Fac. Odontol. USP, São Paulo, v.14, n. 2, p.107-112, abr/jun. 2007.

COSTA, S. M. et al. Dentes Humanos no Ensino Odontológico: Procedência, Utilização, Descontaminação e Armazenamento pelos Acadêmicos da UNIMONTES. R. ABENO, Brasília, v. 7, n. 1, p. 6-12, 2007.

DOMINICl, J. T. et al. Disinfection/Sterilization of Extracted Teeth for Dental Student Use. J. Dental Educ., Washington, v. 65, no. 11, p. 1278-1280, Nov. 2001.

FERREIRA, E. L. et al. Banco de Dentes: Ética e Legalidade no Ensino, Pesquisa e Tratamento Odontológico. Rev. Bras. Odontol., Rio de Janeiro, v. 60, n. 2, p. 120-122, mar/abr. 2003.

GABRIELLI FILHO, P. A.; IMPARATO, J.C.P. Comércio de Dentes. In: IMPARATO, J. C. P. et al. Banco de Dentes Humanos. Curitiba: Maio, 2003. Cap. 10, p. 145-150.

NASSIF, A. C. S. et al. Estruturação de um Banco de Dentes Humanos. Pesq. Odontol. Bras., São Paulo, v. 17, p.70-74, maio 2003a. Supl. 1.

NASSIF, A. C. S et al. Organização e Funcionalidade do Banco de Dentes Humanos da FOUSP. . In: IMPARATO, J. C. P. et al. Banco de Dentes Humanos. Curitiba: Maio, 2003b. Cap. 4, p. 51-82.

RIO GRANDE DO SUL. Ministério Público. Comércio da Morte. Disponível

em: <http://www.mp.rs.gov.br/imprensa/clipping_fonte/clipping/id56076.ht m?impressão $=1 \&>$.

Acesso em: 10 mar. 2009.

SILVA, M. Compêndio de Odontologia Legal. São Paulo: Medsi, 1997.

TIERI, F. et al. Banco de DNA Dentário. In: IMPARATO, J. C. P. et al. Banco de Dentes Humanos. Curitiba: Maio, 2003. Cap. 10, p. 173180.

VANZELLI, M.; IMPARATO, J.C.P. Histórico e Introdução. In: IMPARATO, J. C. P. et al. Banco de Dentes Humanos. Curitiba: Maio, 2003. Cap. 1, p. 21-31.

VANZELLI, M. et al. Valorização do Dente Como um Órgão. In: IMPARATO, J. C. P. et al. Banco de Dentes Humanos. Curitiba: Maio, 2003. Cap. 2, p. 33-36.

WHITE, R. R.; HAYS, G. L. Failure of Ethylene Oxide to Sterilize Extracted Human Teeth. Dent. Mater., Kidlington, v. 11, no. 4, p. 231233, July 1995. 